\title{
Research \\ Eliciting Mental Models: a Comparison of Interview Procedures in the Context of Natural Resource Management
}

\author{
$\underline{\text { Natalie A. Jones }}^{1}, \underline{\text { Helen Ross }}^{1}, \underline{\text { Timothy Lynam }}^{2}$ and $\underline{\text { Pascal Perez }}^{3}$
}

\begin{abstract}
The sustainable management of natural resources largely depends on people's conceptions of environmental systems and how they function. The mental model construct provides an appropriate means to explore the cognitive dimension of people's interactions with such systems. Mental models are cognitive representations of external reality that people use as the basis for acting with and within the world around them. We aimed to improve the application of the mental model construct to the field of natural resource management, with an emphasis on creek, i.e., stream, systems, by exploring how certain elicitation procedures may affect the mental models expressed. One of the initial hurdles that must be overcome is to work out how to effectively elicit people's mental models of complex, dynamic phenomena. By improving their understanding of mental model elicitation procedures, researchers can make better use of the mental model construct to further explore the cognitive and social dimensions of human-environment interactions. The procedures compared were oral interviews and a drawing task with oral commentary, conducted at either a creek location, where visual cues were available, or in the interviewee's home. We found that the location of the interview had a greater effect on the expressed mental models than the interview task. The locations also evoked different emphases in the mental models: those elicited by a creek featured more concepts and were more specific, whereas those elicited at home were typically more generic and dense. The interview task was found to have minimal effect on the mental models expressed.
\end{abstract}

Key Words: drawing; elicitation; interview; mental model; method; natural resource management; oral; transect

\section{INTRODUCTION}

Researchers within the field of natural resource management (NRM) are increasingly recognizing the value of exploring the cognitive dimensions of human-environment interactions (Abel et al. 1998, Walker et al. 2006). In recent years, research attention has been directed away from how people "ought" to make decisions and toward exploring the cognitive structures that underpin people's reasoning, decision making, and behavior (Beratan 2007, Etienne et al. 2011, Mathevet et al. 2011, Lynam et al. 2012). Although environmental cognition, i.e., the study of how individuals structure their thinking about environmental issues, how they learn these cognitions, and how these cognitions influence behaviors (Henry and Dietz 2012), has been a wellestablished domain of research since the work of Moore and Golledge (1976), its application to NRM contexts raises specific methodological challenges. For example, NRM researchers require methods that enable them to study people's conceptions of environmental systems, which are both complex and dynamic. They also require methods that are suitable for use in field settings, as opposed to laboratory settings, and must therefore take into account situational factors that can affect cognition, such as sensory cues and mood (Smith and Semin 2004).

NRM researchers and practitioners are particularly interested in gaining insight into the cognitive structures that frame peoples' interactions with complex and dynamic environments and exploring how these structures may differ between individuals and social groups (Abel et al. 1998, Özesmi and Özesmi 2004, Dray et al. 2006, Baynes et al. 2011, Etienne et al. 2011, Stone-Jovicich et al. 2011, Lynam et al. 2012). The mental model construct has been identified as a suitable means for examining cognition in the context of NRM because it captures how people dynamically conceive environmental systems to function. Mental models are internal cognitive structures that guide people's interactions with the world around them (Craik 1943, Johnson-Laird 1983). Understanding people's mental models can provide key insights into the human management of environmental systems. It is not possible to directly access other people's thinking. Researchers must therefore rely on techniques designed to elicit and represent mental models that do not involve direct observation or measurement. Despite considerable attention to methods of elicitation, little of this has critically examined the effects of different elicitation procedures on expressed mental models (Jones et al. 2011). If the mental model construct is to be used in NRM as a means to explore people's cognition of environmentrelated systems, further research is necessary to enhance our understanding of how elicitation methods and tools can influence the representations made of those mental models, and indeed possibly influence the cognitive structures targeted during the elicitation process (Lynam et al. 2012). We explored the effects of different elicitation procedures on the content and relations of expressed mental models of complex and dynamic phenomena associated with NRM. The term "elicitation" refers to the process of inquiry to encourage a person to externalize a mental model. An "expressed mental model" is that which a person conveys in an interview situation, i.e., through the elicitation process.

\section{MENTAL MODELS AND THEIR ELICITATION}

The psychology and cognitive science literature (Johnson-Laird 1983, Matlin 1998) asserts that people must be able to represent the external world mentally to interact with it. The definition of a mental model as a cognitive representational structure overlaps with a number of other cognitive constructs, such as schema (Brewer and Trevens 1981). A key feature of a mental model that differentiates it from those constructs, however, is that it is a "dynamic" representation that can be run like a simulation, allowing an individual to test different scenarios before acting (Craik 1943). This definition of a mental model is suited to its application within the field of NRM, which features interacting social and ecological processes, and so is the definition we have adopted. We largely focus on the dynamic function of mental 
models because this is what differentiates them from other structures. An overview of how the mental model construct has been used in the field of NRM, including a summary of elicitation procedures applied, is provided by Jones et al. (2011). A review of the NRM literature shows that mental models have been elicited to understand the basis for people's actions (Baynes et al. 2011); to integrate different perspectives to improve the overall understanding of a given system (Özesmi and Özesmi 2004); to explore similarities and differences in stakeholders' understanding to improve communication (Abel et al. 1998); and to support decision-making and negotiation processes in contentious situations (Dray et al. 2006).

A variety of mental model elicitation procedures have been used in different disciplines to suit different research contexts and purposes, including, for example, the study of system dynamics (Doyle et al. 2008), human-computer interaction (Cooke 1999), and risk communication (Morgan et al. 2002). A review of elicitation procedures used reveals that they differ in terms of two key dimensions: (1) a situated and nonsituated dimension and (2) an oral- and visual-based dimension. These dimensions provide a starting point to begin exploring how different interview procedures might affect the mental models people express in an elicitation exercise. The difference between situated and nonsituated procedures concerns the location in which the elicitation interview is conducted. "Situated" procedures involve eliciting a person's mental model in a location corresponding to the phenomena to be elicited, as performed by Abel et al. (1998) for example. A "nonsituated" procedure involves eliciting a person's mental model in a location removed from the phenomena of interest. The majority of mental model elicitation procedures are conducted as a nonsituated interview (Etienne et al. 2011, Stone-Jovicich et al. 2011). That is, mental models are typically elicited in a setting that is convenient for the interviewer and/or interviewee, such as in the participant's home, but not particularly relevant to the topic of the interview. The situated versus nonsituated procedural dimension provides an interesting point of comparison. It enables us to explore what effect the physical context has on the mental representations people form and use in a given situation.

In terms of the oral- and visual-based dimension, Carley and Palmquist (1992) advocate the use of oral-based procedures. They state that the symbolic or verbal structure extracted from a text, such as an interview transcript, can be considered a sample of the full symbolic representation of the individual's cognitive structure. They believe that language provides a "window through which to view the individuals mind" (Carley and Palmquist 1992:603). A common oral-based mental model elicitation technique is the oral interview (Morgan et al. 2002). Other oralbased techniques include semantic proximity and word association tasks (Rowe and Cooke 1995, Langan-Fox et al. 2006).

Kearney and Kaplan (1997) disagree that linguistic structure alone can be taken as representative of an individual's cognitive structure. Instead, they incorporate an imagistic approach to mental model elicitation. Combined oral- and visual-based procedures are theoretically supported by studies that suggest cognition is not only language based and that verbal and imagistic thought are carried out by two distinct, though partly connected, systems (Kearney and Kaplan 1997). Kearney and Kaplan claim that semantic organization in memory may differ from the organization of objects or concepts in memory. The visual/spatial array created through a visual diagramming exercise is believed to be highly compatible with human information processing (Pezdek and Evans, cited in Kearney and Kaplan 1997). Kearney and Kaplan (1997) acknowledge the impact that an interview procedure can have on a person's cognitive ability to access more deeply held beliefs. They suggest that creating a visual representation of one's understanding can help the interviewee explore his or her own mental model through the process of "mapping" it.

\section{METHODS}

We compared four elicitation interview procedures that differ in regard to the two dimensions outlined previously: the location of the interview and the interview task. The procedures compared were (1) an open-ended oral interview task and (2) an open-ended diagrammatic-oral interview task, whereby participants were given the opportunity to represent their understanding visually as well as orally. These two interview tasks were compared in (1) a "situated" and (2) a "nonsituated" context. The former involved conducting the elicitation interview in a location corresponding to the phenomena of interest, providing the interviewee with immediate access to relevant perceptual cues. In this case, the elicitation interviews were conducted in a creek, i.e., stream, location because the interview topic concerned creek systems. The nonsituated interviews were conducted in a neutral location, namely in the interviewee's home, removed from the phenomena of interest. The four combinations were referred to as creek-oral, house-oral, creek-diagrammatic-oral, and house-diagrammaticoral.

Participants in the study were rural and peri-urban dwellers who were members or associates of Noosa and District Landcare, a not-for-profit volunteer-based environment organization based in south-east Queensland, Australia. Forty people were interviewed, i.e., 16 females and 24 males, spanning a range of occupational backgrounds. Participants' ages ranged from mid-20s to late 60 s. People were randomly assigned to 1 of the 4 interview procedures. Some interviewees did not complete the task correctly, so their interviews had to be discounted in different aspects of the data analysis.

Twelve pilot-test interviews were conducted. The pilot-testing phase was important in determining the level of specificity of the topic to be covered and provided a valuable opportunity to devise a set of guidelines for using probing questions.

All four interview procedures were conducted as semistructured interviews. All participants were instructed at the beginning of the interview to respond in general terms. All interviews were audio recorded and transcribed verbatim, and the drawings produced in the oral-diagrammatic procedure retained.

\section{Oral interview procedure}

The following question was posed to participants at the beginning of each semistructured oral interview: "Can you explain to me how you understand the vegetation along the creek to affect water quality?" Probing questions were posed according to the interviewees' responses by following a set of guidelines, mainly involving "how" and "why" questions. Because we are concerned 
with the elicitation of people's understanding of ecological processes, i.e., the effects of vegetation on water quality in creek systems, probing questions also involved asking participants to extend their causal explanations when relevant. For example, interviewees were asked: "Does that have a flow-on effect?" or "What happens then?" Echo, or repetition probing, was also used. To ensure that the interviewee had communicated the extent of his or her mental model, the interviewee was asked: "Does anything else comes to mind?" Once the interviewee indicated that nothing else came to mind, this signaled the completion of the interview.

\section{Diagrammatic-oral interview procedure}

For this procedure, the question was phrased as follows: "Can you explain to me, through a picture or diagram, how you understand the vegetation along the creek to affect water quality?" Participants were provided with a large sheet of paper, a board to lean on, and a variety of colored pens. Participants were asked to draw a picture or diagram to represent their answer to the question. They were told they could use words, pictures, or a combination of both. They were also asked to orally explain the picture or diagram as they drew. The probing questions asked in the oral interviews were also used for this procedure. Logistics were slightly different in the house-diagrammatic-oral and creekdiagrammatic-oral procedures as outlined subsequently.

\section{Creek-based, i.e., situated, interview procedure}

The creek-based interviews took place while at a creek on or adjacent to the interviewee's property. For logistic reasons, one participant was interviewed at a creek in a public location. It was originally intended that all the creek-oral interviews would be conducted as transect interviews (following Abel et al. 1998) and that all the creek-diagrammatic-oral interviews would be conducted as fixed-point interviews because of the logistic difficulties associated with walking and drawing at the same time. Of the creek-oral interviews, 7 interviews were carried out as transects, whereas 3 were fixed-point interviews. This was because of certain limitations that prevented us from walking along the creek, including the thickness of the vegetation, property boundaries, and the lack of access to the creek because of fences. Nine of the 10 diagrammatic-oral interviews involved standing in one location because it was more difficult to walk and draw at the same time.

\section{House-based, i.e., nonsituated, interview procedure}

The house-based interviews took place within the interviewee's home. This procedure was straightforward, with all interviews carried out in a similar manner.

\section{DATA ANALYSIS AND RESULTS}

Transcript data collected from all interviewees were systematically compared to determine whether the interview procedures elicited different responses from participants. Of the 20 interviewees asked to take part in the diagrammatic interviews, 4 chose not to draw a picture because they did not feel comfortable with the task of drawing. The transcripts from these 4 interviews were not analyzed. One creek-oral interview was conducted with a couple rather than an individual. This interview transcript was also discounted.

Four measures were used to examine relationships between elicitation processes and the expressed mental models: The first was the number of concepts expressed in each mental model. The second was the number of functional linkages, i.e., causal relationships, expressed in each mental model. The third was the density of the mental model or the ratio of functional links to concepts. Finally, the fourth was the specificity of the mental model or the proportion of the mental model that was specific versus general.

\section{Number of concepts elicited}

Content analysis was used to determine whether patterns could be identified across the four interview procedures in terms of the "number" of distinct concepts expressed by participants, omitting repetitions. The audio recordings from both the oral and diagrammatic-oral interviews were transcribed and analyzed in the same way. The content analysis coding process involved identifying the concepts within each transcript (Abel et al. 1998). We defined the concept variable as objects or nouns, such as "nutrients" or "soil"; processes, such as "evaporation" or "erosion"; or agents, such as "farmer" or "landowner." An example of the coding process is provided subsequently. The concepts extracted from this segment of text are specified.

"Trees" drop "leaves" on the "ground," and all sorts of
other things. They create a "filter," and when the "water"
goes down to our "creek" and all this "vegetation" here
helps to break the "water" so it doesn't cause "erosion."
It helps to prevent "erosion."

Once all transcripts had been coded and concepts listed in a spreadsheet, synonyms were identified and tagged accordingly. The final spreadsheet showed the complete list of concepts mentioned by all interviewees, which concepts were mentioned by which interviewees, and the synonyms, if any, for each concept. Totals were calculated within the spreadsheet for each of the four interview procedures to show how many interviewees mentioned each concept. Totals were also calculated for interviewees participating in the creek-based interviews, the house-based interviews, the oral interviews, and the diagrammatic-oral interviews. With the counts of concepts reflecting a sparse and highly dispersed data set, a generalized linear model (GLM) with a quasi-Poisson error term and a log link function (Crawley 2007), using the statistical software package R (R Development Core Team 2011), was used to test the effects of the different interview procedures on the number of concepts elicited. The test of significance was based on a Student $t$ test. The model and statistical test used were selected to suit the design, taking into consideration the sample size used and the purpose of the study.

The GLM was applied to the data to explore two factors associated with the experimental conditions: interview location, i.e., creek- versus house-based, and interview task, i.e., diagrammatic-oral versus oral. The question was whether the interview location, the interview task, or an interaction of location and task affected the number and type of concepts elicited. The model also tested whether socio-demographic variables of the interviewees, i.e., age, gender, and occupational background, affected the dependent variable, in this instance, the number of concepts elicited.

The results showed a significant effect of location on the number of concepts expressed in an interview, with the creek-based interviews eliciting more concepts than the house-based 
interviews $($ Table $1 ; \mathrm{T}$ value $=-2.718, \mathrm{p}=0.0104, \mathrm{df}=33, \mathrm{SE}=$ $0.0309)$. There was no statistically significant difference in the number of concepts elicited across the interview tasks, i.e., diagrammatic-oral versus oral.

Table 1. The mean and median number of concepts elicited using the different interview procedures.

\begin{tabular}{lcccc}
\hline \hline Interview Group & Mean & $\begin{array}{c}\text { Standard } \\
\text { Deviation }\end{array}$ & Median & Range \\
\hline Location & & & & \\
Creek & 58 & 19.3 & 56 & $27-112$ \\
House & 43 & 15.7 & 40 & $20-74$ \\
& & & & \\
Type & & & 49 & $25-73$ \\
Diagrammatic-oral & 48 & 15.4 & 50 & $20-112$ \\
Oral & 52 & 21.7 & 50 \\
\hline
\end{tabular}

\section{Number of functional linkages}

The extent to which participants expressed cause-and-effect relationships between concepts was also examined. We referred to cause-and-effect relationships as "functional linkages." Our analysis sought to explore whether the different interview procedures influenced the number of functional linkages expressed by interviewees, as identified in the interview transcripts. It was thus used to go beyond examining what information was contained within the expressed mental models, i.e., objects and concepts, to examining how that information was organized within the expressed mental models (Carley and Palmquist 1992).

The methodological process of systematically extracting relationships from a body of text is not straightforward (Wrightson 1976, Carley 1993, Becu et al. 2003, Dray et al. 2006), requiring the development of a comprehensive coding strategy. In developing a coding strategy for functional linkages, an initial choice involved defining the meaning or type(s) of relationship (s) to be extracted from the text. We defined "functional linkage" as an action or function, typically indicated by a verb, which links two concepts: concept A and concept B. For example, the sentence "the roots hold the bank" is coded as follows: concept A = "roots"; function or action = "hold"; and concept B = "bank." Functional linkages identified in each transcript were recorded in a matrix using Microsoft Excel.

To examine the effects of the elicitation procedure on the counts of functional linkages, a GLM using a quasi-Poisson error term and a log link function was applied to the counts of functional linkages. The effects of interview location, interview task, an interaction of location and task, and socio-demographic variables, i.e., age, gender, and occupational background, on the number of functional linkages was examined.

The number of expressed functional linkages did not differ across the four elicitation procedures (Table 2). There was also no difference across socio-demographic variables.

\section{Mental model density}

Özesmi and Özesmi (2004) assert that the ratio of relationships, i.e., functional linkages, to concepts expressed by participants provides a measure of density. They note that density provides an "index of connectivity," indicating how "connected or sparse" the represented mental models are (Özesmi and Özesmi 2004:50). A high density measure indicates that the interviewee perceives "a large number of causal relationships among the variables" (Özesmi and Özesmi 2004:50).

Table 2. Mean and median number of functional linkages elicited using the different interview procedures.

\begin{tabular}{lcccc}
\hline \hline Interview Group & Mean & $\begin{array}{c}\text { Standard } \\
\text { Deviation }\end{array}$ & Median & Range \\
\hline Location & & & & \\
Creek & 34.31 & 16.75 & 30.5 & $13-72$ \\
House & 33.58 & 18.89 & 28 & $12-81$ \\
& & & & \\
Type & & & 30 & $12-81$ \\
Diagrammatic-oral & 32.88 & 19.19 & 33 & $13-72$ \\
Oral & 34.79 & 16.8 & 33 \\
\hline
\end{tabular}

Density (D), was calculated as the number of connections (C), i. e., functional linkages, by the total number of connections possible (Hage and Harary, cited in Özesmi and Özesmi 2004). The number of possible connections is calculated by counting the total number of concepts mentioned by an interviewee $(\mathrm{N})$ and multiplying this by $\mathrm{N}-1$ because in this analysis a concept cannot form a connection with itself. The equation used to calculate the density of each represented mental model is as follows: $\mathrm{D}=\mathrm{C} /[\mathrm{N}$ $\times(\mathrm{N}-1)]$. A GLM using a quasi-Poisson error term and a $\log$ link function was also applied to the "density" score for each expressed mental model to determine whether a significant difference exists between the interview procedures.

The house-based interviews elicited mental models that were twice as dense as those elicited in the creek-based interviews (Table 3; $\mathrm{T}$ value $=3.319, \mathrm{p}=0.0022, \mathrm{df}=33, \mathrm{SE}=0.2143$ ). Twice as many relations per concept were expressed in the house-based interviews compared to creek-based interviews. No difference was observed in the density of mental models expressed in the diagrammaticoral and oral interview procedures, and density did not vary across the tested socio-demographic variables.

Table 3. Mean and median density value of mental models elicited using the different interview procedures.

\begin{tabular}{lcccc}
\hline \hline Interview Group & Mean & $\begin{array}{c}\text { Standard } \\
\text { Deviation }\end{array}$ & Median & Range \\
\hline Location & & & & \\
Creek & 0.01 & 0.00 & 0.01 & $0.01-0.02$ \\
House & 0.02 & 0.01 & 0.02 & $0.00-0.06$ \\
Type & & & & \\
Diagrammatic-oral & 0.02 & 0.01 & 0.01 & $0.01-0.06$ \\
Oral & 0.02 & 0.01 & 0.01 & $0.00-0.05$ \\
\hline
\end{tabular}

\section{Analysis of perspective: comparison of specific and general} responses

The data were also analyzed to assess whether the different interview procedures influenced the perspective interviewees took in responding to the interview questions. In other words, from what perspective, i.e., more "specific" or more "general," did the interviewee consider the interview topic and respond? 
Analysis of perspective was applied to the oral transcripts by documenting within the transcript whether the interviewee responded in "specific" versus "general" terms. A specific response was defined as a response whereby the interviewee referred to a specific or particular instance of something, such as a specific creek or process that takes place in a particular locale. This type of response referred to a specific localized area or feature of that environment. For example, the following was a specific response: "One good thing about this area is that it can flood, the water can come up but in a day or so it seeps into the ground or just washes off." In this case, the interviewee specified "this area," a particular locale, rather than talking about the effect of flooding in general. If the interviewee did not specify a particular instance, the text was coded as a general response. A general response was an idea without explicit application to a particular instance. For example, a segment of an interview coded as a general response was the following: "The leaves help the water to soak in and I think it provides a mulch on the ground so that when the water hits it, it's not quite so fierce as when it's hitting the soil itself and then the soil is eroding immediately." In this case, the interviewee did not apply the idea to a particular instance or explicitly state a specific situation. The person was speaking in more general or abstract terms about a process.

Transcripts were coded line by line using NVIVO 8. At the completion of the coding process, NVIVO revealed what percentage of the total text document, i.e., the transcript, was assigned to each node. It was then possible to determine what proportion of each interview transcript was coded as "specific" versus "general."

A GLM was again used to determine if the different interview procedures, i.e., the independent variable, influenced whether the interviewee responded more in general or specific terms, or a combination of the two, i.e., the dependent variable. Rather than specifying a quasi-Poisson error, a Gaussian error structure was specified, which defines the mean to variance relationship, because the data displayed a normal distribution.

The GLM analyzed the "specific" response data only because the specific and general response data represented the percentage of an interview transcript coded as "specific" or "general." A small portion of each transcript was also coded as "other." The proportion of an interview in which an interviewee responded in a specific manner was significantly higher in the creek-based interviews $($ median $=73.61 \%)$ than the house-based interviews $($ median $=29.33 \%)($ Table $4 ;$ T value $=-3.135, \mathrm{p}=0.0036, \mathrm{df}=$ $33, \mathrm{SE}=8.547)$. The proportion of responses that were specific, or general, did not vary across tested socio-demographic variables.

\section{DISCUSSION}

The results reveal differences between the creek- and house-based procedures in terms of three of the four measures of mental model content examined. Mental models elicited in creek-based locations had more concepts and were more specific than were mental models elicited in respondents' homes. Mental models elicited in respondents' homes were denser than were mental models elicited at creek sites. The number of functional linkages, i.e., an index of causal relationships, did not differ across the elicitation procedures or across tested socio-demographic variables. None of the measures varied significantly across the diagrammatic versus oral task or across the three sociodemographic variables: age, gender, and occupational experience. Although not based on an extensive data set, the results are sufficiently robust to suggest some clear guidelines for those seeking to work with mental models in an NRM context.

Table 4. Mean and median percentage of the interview transcript coded as a specific response, as elicited using the different interview procedures.

\begin{tabular}{lccc}
\hline \hline Interview Group & $\begin{array}{c}\text { Mean Response (as } \\
\text { a \% of the } \\
\text { interviewee's total } \\
\text { response) }\end{array}$ & $\begin{array}{c}\text { Standard } \\
\text { Deviation }\end{array}$ & Median (\%) \\
\hline Location & 61.93 & 24.77 & 73.61 \\
Creek & 35.13 & 25.54 & 29.33 \\
House & & & \\
Type & 43.02 & 32.45 & 50.41 \\
Diagrammatic-oral & 51.05 & 24.52 & 50.86 \\
Oral & & & \\
\hline
\end{tabular}

For many of the reasons already noted, we still do not know the extent to which people have complete and largely preformed mental models or to which they compile the mental models in response to specific situations (Jones et al. 2011, Lynam et al. 2012). What the data do tell us is that elicited or expressed mental models are highly situation specific both in terms of their content and their structure.

These results have important implications for those seeking to elicit mental models in NRM contexts; depending on where people are when asked what their beliefs are in relation to how some element of the world works, we should expect somewhat different responses. Mental models elicited in home environments are likely to include more general concepts and be denser than mental models elicited in field situations, which are likely to be more specific and contain more concepts. It may be that homebased interviews elicit more "core" or long-term aspects of a person's mental model, whereas field-based interviews are likely to add to this core material more situationally cued content and linkages. Further, because mental models can be partially individual and partially shared (Lynam et al. 2012), the content elicited in home-based interviews may lean toward socially constructed and shared knowledge, aspects of creek behavior that would be well recognized among study participants. We suggest that the purpose of eliciting mental models should be an important determinant of these decisions. For instance, researchers or practitioners may be interested in understanding the kind of mental models that will be brought into play in formulating general plans, e.g., environmental management in a region, or taking specific actions, e.g., restoration of a specific creek.

Consistent with the model of Lynam et al. (2012), we would expect that where people need to rely on socially shared knowledge for their mental models, i.e., in the absence of situated cues, as in the home situation, the elicited mental models would be more similar or consensual across respondents, this consensuality reflecting the underlying shared conceptions. We have observed this for groups that work closely together on issues (Mathevet et al. 2011) 
as well as those that share similar cultural orientations (StoneJovicich et al. 2011).

Mental models may also be elicited to explore the similarities and differences in understanding to improve communication between stakeholders (Abel et al. 1998). Specific mental models may be elicited in the initial stages of a project to broadly scope stakeholders' understandings. Eliciting a greater number of concepts provides greater opportunity for identifying overlap and difference in the concepts that feature in stakeholders' mental models, as well as the links present or absent in underlying dynamics. This provides greater opportunity for identifying similarities and differences in stakeholders' understanding.

The elicitation of more generic mental models, on the other hand, may be suited to research that deals with highly contentious issues to better understand and work through the fundamental similarities and differences in stakeholders' mental models. Communication is improved when there is a shared understanding (Abel et al. 1998). Identifying overlap in understanding within deeply held generic mental models can provide a solid foundation on which discussions can take place. More deeply ingrained differences are also revealed, indicating areas that may require greater attention and focus in stakeholder interventions. Through eliciting both more general and more situationally cued and individualized mental models, practitioners and researchers may be able to identify the common, i.e., shared, elements of mental models, as well as the individualized elements, and through this analysis establish the accepted and conflicted regions of the mental models.

Interestingly, we found no significant difference between the interview tasks, i.e., diagrammatic-oral versus oral, in terms of the content or relations of expressed mental models. This is an interesting finding in that, theoretically, elicitation techniques that use a combination of oral and diagrammatic tasks are believed to tap two different modes of cognition: oral and visual (Kearney and Kaplan 1997). We selected a diagrammatic-oral technique for comparison because it was anticipated that it would assist individuals to express their mental models and thus elicit more concepts and relationships. Our findings do not support these assumptions because no significant difference was identified between the mental models expressed in the diagrammatic-oral versus oral-based interviews. This could be attributable to either the challenge of representing a dynamic phenomenon, i.e., a dynamic creek, on a two-dimensional, static visual-based medium, i.e., using pen on paper, or our small sample size.

\section{CONCLUSIONS}

We have shown that location is an important factor in the elicitation of mental models. NRM practitioners should thus take into consideration how the physical environment in which they conduct a mental model elicitation exercise may influence the mental models they elicit. The location of the interview can be selected according to the aims of the research. In projects that opt for situated elicitation procedures, it is important for practitioners to account for the logistic issues, such as weather conditions and site accessibility, that arise when conducting fieldwork in natural environments.

Our results found no support for differences in oral or combined diagrammatic-oral procedures for eliciting mental models and hence call into question the effectiveness of drawing tasks in particular to elicit mental models. Further research is required to determine in what research contexts and with which participants drawing tasks work well.

Mental models remain an important concept for NRM researchers and NRM practitioners alike because they seek to understand how people think about natural resources systems. With care and sensitivity to purpose and context, currently available tools and analytical procedures provide the means to gain rich insights into the cognitive worlds of resource users and managers.

Responses to this article can be read online at: http://www.ecologyandsociety.org/issues/responses. $\mathrm{php} / 6248$

\section{Acknowledgments:}

The lead author would like to thank the University of Queensland and HEMA Consulting Pty. Ltd. for funding this research.

\section{LITERATURE CITED}

Abel, N., H. Ross, and P. Walker. 1998. Mental models in rangeland research, communication and management. Rangeland Journal 20:77-91.

Baynes, J., J. Herbohn, and I. Russell. 2011. The influence of farmers' mental models on an agroforestry extension program in the Philippines. Small-scale Forestry 10:377-387. http://dx.doi. org/10.1007/s11842-010-9154-7

Becu, N., F. Bousquet, O. Barreteau, P. Perez, and A. Walker. 2003. A methodology for eliciting and modelling stakeholders' representations with agent based modelling. Lecture Notes in Artificial Intelligence 2927:131-149.

Beratan, K. K. 2007. A cognition-based view of decision processes in complex social-ecological systems. Ecology and Society 12(1): 27. [online] URL: http://www.ecologyandsociety.org/vol12/iss1/ art271

Brewer, W. F., and J. C. Treyens. 1981. Role of schemata in memory for places. Cognitive Psychology 13:207-230. http://dx.doi. org/10.1016/0010-0285(81)90008-6

Carley, K. 1993. Coding choices for textual analysis: a comparison of content analysis and map analysis. Sociological Methodology 23:75-126. http://dx.doi.org/10.2307/271007

Carley, K., and M. Palmquist. 1992. Extracting, representing and analyzing mental models. Social Forces 70:601-636. http://dx.doi. org/10.1093/sf/70.3.601

Cooke, N. 1999. Knowledge elicitation. Pages 479-509 in F. T. Durso, R. S. Nickerson, S. T. Dumais, S. Lewandowsky, and T. J. Perfect, editors. Handbook of applied cognition. Wiley, Chichester, UK.

Craik, K. J. W. 1943. The nature of explanation. Cambridge University Press, Cambridge, UK. 
Crawley, M. J. 2007. The $R$ book. John Wiley and Sons, West Sussex, UK.

Doyle, J. K., M. J. Radzicki, and W. S. Trees. 2008. Measuring change in mental models of complex dynamic systems. Pages 269-294 in H. Qudrat-Ullah, J. M. Spector, and P. I. Davidsen, editors. Complex decision making: theory and practice. SpringerVerlag, Berlin, Germany. http://dx.doi.org/10.1007/978-3-540-73665-3_14

Dray, A., P. Perez, N. Jones, C. Le Page, P. D’Aquino, I. White, and T. Auatabu. 2006. The AtollGame experience: from knowledge engineering to a computer-assisted role playing game. Journal of Artificial Societies and Social Simulation 9:6.

Etienne, M., D. R. Du Toit, and S. Pollard. 2011. ARDI: a coconstruction method for participatory modeling in natural resources management. Ecology and Society 16(1): 44. [online] URL: http://www.ecologyandsociety.org/vol16/iss1/art44/

Henry, A. D., and T. Dietz. 2012. Understanding environmental cognition. Organization \& Environment 25:238-258. http://dx.doi. org/10.1177/1086026612456538

Johnson-Laird, P. N. 1983. Mental models. Cambridge University Press, Cambridge, UK.

Jones, N. A., H. Ross, T. Lynam, P. Perez, and A. Leitch. 2011. Mental models: an interdisciplinary synthesis of theory and methods. Ecology and Society 16(1): 46. [online] URL: http:// www.ecologyandsociety.org/vol16/iss1/art46/

Kearney, A. R., and S. Kaplan. 1997. Toward a methodology for the measurement of knowledge structures of ordinary people: the conceptual content cognitive map (3CM). Environment and Behavior 29:579-617. http://dx.doi.org/10.1177/0013916597295001

Langan-Fox, J., C. Platania-Phung, and J. Waycott. 2006. Effects of advance organisers, mental models and abilities on task and recall performance using a mobile phone network. Applied Cognitive Psychology 20:1143-1165. http://dx.doi.org/10.1002/ acp. 1258

Lynam, T., R. Mathevet, M. Etienne, S. Stone-Jovicich, A. Leitch, N. Jones, H. Ross, D. Du Toit, S. Pollard, H. Biggs, and P. Perez. 2012. Waypoints on a journey of discovery: mental models in human-environment interactions. Ecology and Society 17(3): 23. http://dx.doi.org/10.5751/ES-05118-170323

Mathevet, R., M. Etienne, T. Lynam, and C. Calvet. 2011. Water management in the Camargue Biosphere Reserve: insights from comparative mental models analysis. Ecology and Society 16(1): 43. [online] URL: http://www.ecologyandsociety.org/vol16/iss1/ art43/

Matlin, M. W. 1998. Cognition. Fourth edition. Harcourt Brace College, New York, New York, USA.

Moore, G. T., and R. G. Golledge. 1976. Environmental knowing: concepts and theories. Pages 3-24 in G. T. Moore and R. G. Golledge, editors. Environmental knowing: theories, research and methods. Dowden, Hutchinson, \& Ross, Stroudsburg, Pennsylvania, USA.

Morgan, M. G., B. Fischhoff, A. Bostrom, and C. J. Atman. 2002. Risk communication: a mental models approach. Cambridge University Press, New York, New York, USA.
Özesmi, U., and S. L. Özesmi. 2004. Ecological models based on people's knowledge: a multi-step fuzzy cognition mapping approach. Ecological Modelling 176:43-64. http://dx.doi. org/10.1016/j.ecolmodel.2003.10.027

R Development Core Team. 2011. R: a language and environment for statistical computing. R Foundation for Statistical Computing, Vienna, Austria.

Rowe, A. L., and N. J. Cooke. 1995. Measuring mental models choosing the right tools for the job. Human Resource Development Quarterly 6:243-255. http://dx.doi.org/10.1002/hrdq.3920060303

Smith, E. R., and G. R. Semin. 2004. Socially situated cognition: cognition in its social context. Advances in Experimental Social Psychology 36:53-117. http://dx.doi.org/10.1016/S0065-2601(04) $\underline{36002-8}$

Stone-Jovicich, S. S., T. Lynam, A. Leitch, and N. A. Jones. 2011. Using consensus analysis to assess mental models about water use and management in the Crocodile River catchment, South Africa. Ecology and Society 16(1): 45. [online] URL: http://www. ecologyandsociety.org/vol16/iss1/art45/

Walker, B. H., L. H. Gunderson, A. P. Kinzig, C. Folke, S. R. Carpenter, and L. Schultz. 2006. A handful of heuristics and some propositions for understanding resilience in social-ecological systems. Ecology and Society 11(1): 13. [online] URL: http://www. ecologyandsociety.org/vol11/iss1/art13/

Wrightson, M. T. 1976. The documentary coding method. Pages 291-332 in A. Axelrod, editor. Structure of decision: the cognitive maps of political elites. Princeton University Press, Princeton, New Jersey, USA. 